\title{
Garrett's Ranking Analysis of Various Clinical Bovine Mastitis Control Constraints in Villupuram District of Tamil Nadu
}

\author{
R. John Christy \\ Assistant Professor Division of Animal Husbandry Faculty of Agriculture Annamalai University Annamalai \\ Nagar - Pin 608002
}

\begin{abstract}
Economic losses due to mastitis are recognized worldwide as a major problem on dairy farms and mastitis limits enhanced milk production efficiency in many dairy herds despite the amount of knowledge available on the subject. This study was conducted with an objective to assess the farmers ranking on various clinical bovine mastitis control constraints in Villupuram District of Tamil Nadu which was randomly selected for the present study. The mastitis control measures practiced in the study area was analysed, in term of frequency or percentage (\%) and rank order was given for a particular measure. Garett's ranking technique was followed to analyse the constraints to control mastitis as perceived by the dairy farmers. Out of 1000 dairy farmers contacted, 120 farmers experienced mastitis incidence during the study period indicating overall clinical mastitis incidence of 12 per cent.Washing udder before and after milking, practicing good hygiene, treatment of clinical cases, culling chronic cases, teat dipping and dry cow therapy were found to be the most popular methods used by the farmers to control mastitis in the study area. High treatment costs, shortage of labour and difficulty in diagnosis were the top three constraints ranked by the farmers in the study area. To minimise the avoidable loss due to the mastitis, Planners should take suitable steps to remove the constraints identified
\end{abstract}

Key Words : Mastitis, Constraints in control of Mastitis, Garett's ranking technique

\section{Introduction}

Smallholder dairy production in India contributes significantly to the incomes of the poor and middle class urban dwellers, who typically keep only few cows. Livestock sector provides employment to many people and nearly 70 per cent of them are women (Subbarama Naidu, 2004). Diseases and parasites are serious constraints affecting dairy cattle production and these diseases affect livestock production in various ways, such as reduced growth rate, milk production, fertility and value of hides and mortality, thus cause considerable economic losses to livestock keepers (Chenyambuga, et al., 2010). Economic losses due to mastitis are recognized worldwide as a major problem on dairy farms and mastitis limits enhanced milk production efficiency in many dairy herds despite the amount of knowledge available on the subject (Hogeveen 2005). Occurrence of mastitis is a complicated problem associated with almost every conceivable factor of management and the environment (Blood and Radostitis 1989).

A farmer who knows that mastitis causes production inefficiencies and extra additional costs can be motivated to act on mastitis prevention (Valeeva et al., 2007). Disease control and prevention decisions are often based on the farmer's perception and knowledge level on mastitis control measures. Perception refers to what a farmer thinks as correct. For effective mastitis control, farmers' perceptions of disease risk, different control measures to practice, constraints and the inherent benefits associated with available disease control options are important criteria in adoption decisions (Gnanasekar and Christy, 2013). Therefore, this study was conducted with an objective to assess the farmers ranking on various clinical bovine mastitis control constraints in the study area.

\section{Methodology}

Villupuram District of Tamil Nadu was randomly selected for the present study. Multistage random sampling technique was used to select the herds. The selected district comprised 22 blocks of which, two blocks, viz., Kallakurichi and Thiyagadurgam were randomly selected. In the next stage, two villages from each selected block were chosen randomly. In total, 1000 farmers having dairy herd size of 2 to 8 were chosen again randomly from the selected blocks, 500 from each block. Among 1000 dairy farmers, 120 dairy farmers experienced mastitis incidence during the study period. The study was taken up during the months of April and May, 2012 and the data collected from the sample units related to the year 2011-2012. Relevant data were collected from the chosen respondents through personal interview using a pre-tested interview schedule. Cross checks were made to minimize the errors due to recall bias and also to ensure reliability of the information provided by the respondents. 
The mastitis control measures practiced in the study area was analysed, in term of frequency or percentage (\%) and rank order was given for a particular measure. Garett's ranking technique was followed to analyse the constraints to control mastitis as perceived by the dairy farmers. The farmers were asked to rank the various mastitis control constraints. These orders of merit were transformed into units of scores by using the following formula.

$$
\text { Per cent position }=\frac{100(\mathrm{Rij}-0.50)}{\mathrm{Nj}}
$$

Where,

Rij - Rank given for the ith factor by the jth individual

$\mathrm{Nj}$ - Number of factor ranked by the jth individual.

The percent position is converted into scores by referring to the table given by Garett and Woodworth (1969). Then for each factor the scores of the individual respondents were added together and divided by the total number of respondents for whom scores were added. These mean scores for all the factors were arranged in descending order and the most influencing factors were identified through the ranks assigned.

\section{Results And Discussions}

Out of 1000 dairy farmers contacted, 120 farmers experienced mastitis incidence during the study period indicating overall clinical mastitis incidence of 12 per cent which was in line with 13.01 per cent reported by Thirunavkkarasu (1996). However Taneja et al. (1989) and Jadhav (1995) found a higher incidence in crossbred cows (23.56 per cent). Improved hygienic measures practiced might be a reason for the lower incidence in the study area.

Washing udder before and after milking, practicing good hygiene, treatment of clinical cases, culling chronic cases, teat dipping and dry cow therapy were found to be the most popular methods used by the farmers to control mastitis in the study area ( Table-1). This finding is similar to the findings of Byarugaba et al. (2003) except the fact that the treatment of clinical cases was the most popular method to control mastitis in Uganda. Decreased incidence of the mastitis due to other measures might made it third most popular control measure in the study area.

Dairy farmer's ranking of various constraints to control clinical bovine mastitis is presented in the Table-2. High treatment costs, shortage of labour and difficulty in diagnosis were the top three constraints ranked by the farmers in the study area. The high costs of treatment can partly be related to the high resistance of the common and cheap antibiotics (Byarugaba et al. ,2003). Shortage of skilled labour and higher wage rate made it very difficult to practice routine disease preventive measures that might have prevented the occurrence of mastitis.

\section{Conclusion}

It has been suggested that mastitis can never be eradicated from dairy operations and its occurrence can only be minimized to acceptable levels (Blood and Radostitis 1989). There are variations in the type of constraints that farmers face related to their ability to comprehend the problem, accessibility to control supplies and sophistication of farming enterprises as well as management routines (Byarugaba et al. ,2003). To minimise the avoidable loss due to the mastitis, Planners should take suitable steps to remove the constraints identified. Conducting more number of awareness programmes through mass media in prime time, conducting more number of livestock rearing and disease control training programmes at the village level and organizing more intensive veterinary camps may save the animals from mastitis thereby helping poor farmers.

\section{Reference}

[1]. Blood D C and Radostits O M 1989 Veterinary Medicine. A Textbook of the Diseases of Cattle, Sheep, Pigs, Goats and Horses. 7th Edition, E L B S/Bailliere Tindall. London.

[2]. Byarugaba D K, Nakavuma J L, Vaarst M and Laker C 2008: Mastitis occurrence and constraints to mastitis control in smallholder dairy farming systems in Uganda. Livestock Research for Rural Development. Volume 20, Article \#5.Retrieved March 30, 2014, from http://www.lrrd.org//rrd20/1/byar20005.htm

[3]. Chenyambuga, S.W., C.Waiswa, M.Saimo, P.Ngumi and P.S.Gwakisa, 2010. Knowledge and perceptions of traditional livestock keepers on tick-borne diseases and sero-prevalence of Theileria parva around Lake Victoria Basin. Livestock Research for Rural Development 22: 7.

[4]. Garett H E and Woodworth RS 1969. Statistics in psychology and education. Vakils, Feffer and Simons Pvt. Ltd., Bombay. p.329.

[5]. Gnanasekar, R. and R. J. Christy, 2013. Knowledge level of livestock keepers on clinical mastitis control measures in Villupuram District of Tamil Nadu . Journal of Extension Education 25(1): 4999-5003

[6]. Hogeveen H (Editor) 2005 Mastitis in Dairy Production: Current knowledge and future solutions, Wageningen Academic Publishers, The Netherlands

[7]. Jadhav, K.L., Tripathi, V.N. \& Kale, M.M. 1995. Incidence and economics of mammary disorders in Holstein Sahiwal crossbred cows. Indian Journal of Dairy Sciences, 48(5): 382-385.

[8]. Subbarama Naidu, A and N.Kondaiah, 2004. Livestock production and post production systems - Need for a pragmatic approach. Ind.Jour.Agril. Mktg (Conf. Spl.)., 18: 91-105. 
[9]. Taneja, U.K., Dwivedi, V.K., Saxena, M.M., Nivsarkar, A.E. \& Nautiyal, L.P. 1989. Incidence of mastitis and production losses in crossbreds. Indian Journal of Animal Science, 59(10): 1346 - 1348

[10]. Thirunavukkarasu, M. 1996 Economic analysis of Mastitis in Dairy Farms, Ph.D. Thesis, Tamil Nadu Veterinary and Animal Sciences University.

[11]. Valeeva, N.I., T.J.G.M.Lam and H.Hogeveen, 2007. Motivation of dairy farmers to improve mastitis management. Journal of Dairy Science., 90: 4466-4477.

Table : 1 Popular methods used to control mastitis in the study area

\begin{tabular}{|l|l|}
\hline Control measures & Number of Farmers \\
\hline Treatment of clinical cases & 120 \\
& $(12)$ \\
\hline Washing udder before and after milking & 820 \\
& $(82)$ \\
\hline Practicing good hygiene & 800 \\
& $(80)$ \\
\hline Culling chronic cases & 75 \\
\hline Teat Dipping & $(7.5)$ \\
\hline Dry cow therapy & 50 \\
& $(5.0)$ \\
\hline
\end{tabular}

Figures in the parentheses indicate percentages to total of 1000 respondents.

Table - 2 Ranking of various clinical bovine mastitis control constraints in the study area

\begin{tabular}{|l|l|l|}
\hline Constraints & Garrett's Mean Score & Ranking \\
\hline High treatment costs & 73.13 & I \\
\hline Shortage of labour & 67.41 & II \\
\hline Difficulty in diagnosis poor environmental & 62.20 & III \\
\hline $\begin{array}{l}\text { Prevalence of p5.80 } \\
\text { hygiene }\end{array}$ & 47.56 & IV \\
\hline Difficulty in accessing veterinary services & 41.59 & V \\
\hline Low productivity of animals & 34.73 & VI \\
\hline $\begin{array}{l}\text { Low household income } \\
\text { Lack medicine, chemicals and } \\
\text { equipments to control mastitis }\end{array}$ & 21.51 & VII \\
\hline
\end{tabular}

